\title{
AIRCRAFT GROUND ICING AND DE-ICING PROCESSES AS MECHANISMS OF THE MOTION IN MIRCE MECHANICS
}

\author{
Dr Jezdimir Knežević* \\ The MIRCE Akademy, Exeter, United Kingdom
}

Mirce Mechanics is a scientific theory of the motion of in-service systems through Mirce Spacetime that enables prediction of the work done by them to be made by using Mirce Equations. However, practical applications of Mirce Mechanics are possible only, when the physical mechanisms that generate the motion of systems through positive and negative states are understood. The mechanism of ice building on an aircraft on the ground is addressed in this paper, as a cause of occurrence of a negative in-service event. It is generated under certain environmental conditions when precipitation falling onto the aircraft freezes, mainly on upper surfaces of the wing and tail, endangering the flight safety. This type of negative events is followed by de-icing process of the aircraft at the airport, as a physical mechanism that causes the transition of an aircraft from the negative to the positive in-service state. Several de-icing methods are presented in this paper together with the analysis of their impacts on aircraft and environment.

Key words: Aircrafts, IC, Mechanization, Motioner, Service

\section{INTRODUCTION}

Aerospace Engineering is one of the major branches of engineering that is concerned with the application of the science and technology to research, design, development, construction, testing, of aircraft and spacecraft. Aerodynamics, which is the bed rock of aerospace engineering, is concerned with studies of the motion of air, particularly when it interacts with a solid object, such as an airplane wing. Formal aerodynamics study in the modern sense began in the eighteenth century, although observations of fundamental concepts such as aerodynamic drag have been recorded much earlier. Most of the early efforts in aerodynamics worked towards achieving heavier-than-air flight, which was first demonstrated by Wilbur and Orville Wright in 1903. Since then, the use of aerodynamics through mathematical analysis, empirical approximations, wind tunnel experimentation, and computer simulations has formed the scientific basis for ongoing developments in heavier-than-air flight and a number of other technologies.

While, aerodynamics is the scientific foundation of the functionality performance of aircraft, Mirce Mechanics is a scientific theory for the motion of in-service systems through Mirce Spacetime. Its axioms, mathematical formulas, rules and methods enable predictions of the work done by the system on one hand and the work done on the system, to keep it going, on the other.

From the Mirce Mechanics point of view, at any instant of time a system can be in one of the following two states of the functionability space [11]:

- Positive State (PS) is the state in which a system is being able to deliver functionality (function, performance and attributes);

- Negative State (NS) is the state in which a system in not being able to deliver functionality.

Consequently, the in-service life of a maintainable system could be considered as motion of system through functionability states, which is governed by the occurrence of functionability events, which are classified as:

- Positive Events (PE) which cause the change of transition from NS to PS;

- Negative Events (NE) which cause the transition from PS to NS.

Humans' ability to travel by air in winter is heavily dependent on de-icing process, which started in 1920's when airplanes used to be de-iced with

* The Mirce Akademy, Woodbury Park, Exeter, EX5 1JJ, United Kingdom; 
a rope, with tied knots in it, which were dragged over the wings to regain their flight worthiness. Today, it is routine process repeated hundreds of times a day during the winter months. For example, the United Airlines despatch team at the Chicago O'Hare airport in 2011 de-iced 12,000 airplanes and about 14,000 in the 2012. Hence, the total number of aircraft de-iced by all operators on all the world airports is measured in millions. [03]

The deadly crash of Air Florida Flight 90 in Washington D.C. in January of 1982 was a harsh reminder of the importance of proper de-icing. Seventy-eight people died when the Boeing 737 lost altitude, struck a crowded bridge, and plunged into the icy Potomac River. The plane had been de-iced, but with the wrong chemical mix, together with delays brought on by heavy snow allowed new ice to coat the wings. [04]

Consequently, the main objective of Mirce Mechanics is the scientific understanding of the physical mechanisms that generate positive and negative events, resulting from atomic processes, environmental impacts or human actions. In this paper a physical process of ice formation of aircraft surfaces and its removal are addressed. Ice builds up on aircraft in two ways: in flight or on the ground. On the ground, precipitation falls onto the airplane and freezes on upper surfaces of the wings and tail. The ground forming ice is managed by de-icing the plane with a fluid, typically propylene glycol, at the airport, imminently to the take off. Hence, this paper addresses the icing and de-icing processes as one of the physical mechanisms that cause the motion of an aircraft through Mirce Spacetime.

\section{AIRCRAFT ICING ON THE GROUND AS A NEGATIVE MECHANISMS}

Aircraft on the ground is exposed to the ground conditions, everywhere in the world. However, in some of these environmental conditions frozen contaminants could cause critical control surfaces to be rough and uneven, disrupting smooth air flow and greatly degrading the ability of the wing to generate lift, and increasing drag. This situation can cause a crash. Large pieces of ice separate from the moving aircraft can cause catastrophic failure by being ingested in engines or damaging propellers. Also, frozen contaminants can jam control surfaces, preventing them from moving properly. Consequently, due to potential severe risk, [10] de-icing of control surfaces on aircrafts affected is performed at airports where temperatures are likely to be around $0^{\circ} \mathrm{C}$, has to be understood and managed accordingly.

\section{The Ice Formation}

The formation of ice attached to the external surface of an aircraft or to the surfaces within its engine air intakes, requires that liquid water drops impact the surface involved. Usually, that moisture must be supercooled, that is it must be in liquid form below $0^{\circ} \mathrm{C}, 273.15 \mathrm{~K}, 32^{\circ} \mathrm{F}$ or $491.67^{\circ} \mathrm{R}$. Main processes of ice formation are addressed below. [05]

\section{Ice from Supercooled Moisture}

The main cause of ice accretion on the external parts of an aircraft is the impact of supercooled water droplets of various sizes on the aircraft. This may happen within cloud or when flying through precipitation. The reason why water droplets do not all freeze as soon as the ambient temperature falls below $0^{\circ} \mathrm{C}$ is the release of latent heat as water changes state to ice. The amount of latent heat released impacts the change of the state so that it takes place progressively as temperature continues to fall. This continues until around $-20^{\circ} \mathrm{C}$ when the most of, by now supercooled, water has turned to ice. Ice grains which have already fully formed and are dry when they impact an aircraft do not adhere but simply bounce off. Therefore, the relative severity of ice accretion can be expected to progressively decrease as ambient temperature reduces below $0^{\circ} \mathrm{C}$ so that little, if any, risk of accretion remains below $-20^{\circ} \mathrm{C}$.

The following two factors are important in respect of supercooled water droplets:

- The extent of their presence, which affects the rate of any ice accretion,

- The size of a droplets, which affects the severity of that accretion by adversely influencing its rate.

Both the quantity and the droplet sizes of supercooled water in cloud are greatest at temperatures just below $0^{\circ} \mathrm{C}$ and both decrease as temperature falls. The size of the supercooled water droplets is very important in respect of the potential to induce ice accretion. Larger droplets have greater inertia and are less influenced by the airflow around the aircraft than smaller droplets so they impinge on larger areas of the aircraft surface than smaller droplets. 
This is especially the case when the in-flight air flows around the leading edge of wings and empennage. Also, it is the larger droplets that produce clear or glaze ice, which is well recognised form of ice and of the most concern as it is often the most difficult to detect visually.

\section{Clouds and Supercooled Moisture}

The majority of supercooled droplets in clouds are between $0.001 \mathrm{~mm}$ and $0.05 \mathrm{~mm}$ in diameter. Layer (stratiform) clouds typically contain average droplet diameters of up to 40 microns. Vertically developed (cumuliform) clouds of moderate scale typically have average droplet diameters of up to $0.05 \mathrm{~mm}$, but large Cumulonimbus clouds often contain much more liquid water, including large quantities in droplets with diameters up to and beyond $0.1 \mathrm{~mm}$.

\section{Freezing Drizzle and Freezing Rain}

Freezing drizzle is related to the supercooled precipitation droplets, with a diameter between $0.05 \mathrm{~mm}$ and $0.5 \mathrm{~mm}$ that are clear of cloud, whereas freezing rain is related to the droplets that exceed $0.5 \mathrm{~mm}$ in diameter. Freezing rain often has much larger droplets which go up to $2 \mathrm{~mm}$ diameter or more, although if they get much beyond $6 \mathrm{~mm}$ in diameter, they will tend to break up.

Freezing rain below cloud forms when rain droplets are supercooled by passage through a layer of air which has a sub-zero temperature. Since air temperatures normally increase as altitude reduces, freezing rain implies the existence of an air temperature inversion. Such conditions can occur below an advancing warm front or a warm occlusion where a relatively warm air mass is overrunning colder air. The existence of freezing rain normally means that there will be warmer air above $0^{\circ} \mathrm{C}$.

\section{Effects of Icing on Aircraft}

The aerodynamic effectiveness of an airframe requires that it begins flight with critical surfaces free from contamination by frozen or semi-frozen moisture, commonly known as the 'clean aircraft' concept.

Failure to remove contaminants from an aircraft and/or to protect it from acquiring further contamination before it becomes airborne may result in sudden loss of control at or shortly after take off. In the case of aircraft with rear mounted engines, any ice on the inner wings of an aircraft at take off may be shed and ingested into the engines causing a partial or total loss of thrust. Also, small patches of ice or frost can result in localised, asymmetrical stalls on the wing, which can result in roll control problems during lift off. Intake duct deposits and engine blade deposits may detach and be ingested by the engine(s) during the subsequent application of high power settings for takeoff, with consequential adverse effects on engine operation, and possible flameout.

\section{Airliner Crashed Due to Failure to De-Ice Plane}

The crash of a Russian-operated regional airliner, in April 2013, that killed 31 people was caused by failure to de-ice the aircraft before flight, was the verdict of crash investigators [10]. The Frenchbuilt ATR72 turboprop operated by the UTair airline crashed just after take-off from the Siberian city of Tyumen's Roshchino Airport with 43 people on board. The immediate cause of the crash was "the flight captain's decision to fly without conducting a de-icing procedure," the Interstate Aviation Committee (MAK) said in its final report [11], adding ice was detected by the crew on the aircraft's surfaces as late as when it was taxiing for departure. Environmental conditions at the airport in the hours before the crash were cold, with temperatures of around 0 degrees Celsius, with freezing rain and snow. According to the report, a mechanic went into the cockpit just before flight and told the pilots: "the plane is clean." The aircraft commander replied "OK, we won't wash it with de-icer fluid then, we'll take off as it is."

After takeoff, the ATR72 climbed to an altitude of some 210 meters, but then banked 35 degrees to the right and then over to the left, reaching over 50 degrees of bank by the time it hit the ground. The report attributed the steep banking to "ice and snow deposits" on the aircraft's lifting surfaces, which affected the plane's aerodynamics.

It is necessary to stress that this example is just one of many that take place all over the world, year after year, in accordance to the well established weather pattern.

\section{The Ice Detection}

In many situations it is almost impossible to determine by observation whether a wing is wet or has a thin film of ice. A very thin film of ice or frost will degrade the aerodynamic performance of any airplane. Ice accumulation on the wing 
upper surface may be very difficult to detect from the cockpit, cabin, or front and back of the wing because it is clear/white.

Accident history shows that non-slatted, turbojet, transport-category airplanes have been involved in a disproportionate number of takeoff accidents where undetected upper wing ice contamination has been cited as the probable cause or sole contributing factor.

Majority of pilots understand that visible ice contamination on a wing can cause severe aerodynamic and control penalties, but it is apparent that many pilots do not recognise that minute amounts of ice adhering to a wing can result in similar penalties[05].

Despite evidence to the contrary, these beliefs may still exist because many pilots have seen their aircraft operate with large amounts of ice adhering to the leading edges and consider a thin layer of ice or frost on the wing upper surface to be more benign.

\section{AIRCRAFT GROUND DE-ICING PROCESS AS A POSITIVE MECHANISMS}

De-icing is defined as removal of snow, ice or frost from aircraft surfaces, while anti-icing is considered to be the application of chemicals that not only de-ice, but also remain on a surface and continue to delay the reformation of ice for a certain period of time, or prevent adhesion of ice to make mechanical removal easier.

At many airports, de-icing is done away from the gate at an area called the deice pad, due to some of the following reasons:

Airlines don't want their planes sitting at the gate any longer than they have to. If another plane is waiting to come into that gate, de-icing a departing plane will only slow down that process.

- De-icing fluids deplete the oxygen from water, and airports don't want the fluids going into the storm water drains. So at the deice pad, the fluids drain into a special tank or reservoir

- De-icing fluid is very slippery, so it poses a safety hazard for people walking or working in the area.

- Airport gates are often congested by other ground vehicles, so it's easier for the deice trucks to move around freely out at the deice pad.

Once a plane is pushed back from the gate, the pilots taxi the plane to the deice pad. A dedicated radio frequency is used so that the pilots can tell the deice crew exactly what they want done to the plane. Some airlines use their own employees to deice planes, and some hire contractors.

Deice fluids are applied methodically, from the wing's leading edge to the trailing edge, beginning at the wingtip and working back toward the wing root, in cases where the wing is joined to the fuselage. The same is done to the horizontal stabilisers. Regarding the tail, they go from front to back, starting at the top of the tail and work their way down to the base. Anywhere from one to four deice trucks can be used to deice a plane.

As a part of de-icing process it is required for a pilot to temporarily disable the aircraft's ventilation system to prevent fluid fumes from entering the cabin. Although the fumes are considered nontoxic for inhalation, it is necessary to keep the odour out of the cabin regardless.

\section{DE-ICING METHODS}

De-icing process consists of mechanical methods (scraping, pushing); application of heat; use of dry or liquid chemicals designed to lower the freezing point of water (various salts or brines, alcohols, glycols); or a combination of some of these different techniques.

Anti-icing of aircraft is accomplished by applying protective layers over a surface, using a viscous fluid called anti-ice fluid, to absorb contaminate. All anti-ice fluids offer only limited protection, dependent upon frozen contaminant type and prevailing weather conditions. A fluid has failed when it no longer can absorb the contaminant and it essentially becomes a contaminant itself. Even water can be a contaminant in this sense, as it dilutes the anti-icing agent until it is no longer effective.

\section{Mechanical and Non-chemical De-icing Method}

Mechanical and other nonchemical methods used to deice aircraft include brooms, ropes, hot water, infrared heating, and forced air. Brooms and ropes are not the primary method of aircraft deicing, especially wet-weather de-icing, because they are so time- and labour-intensive, but rather used in combination with chemical de-icing.

The most frequently used methods are:

- Forced air or hot air systems are used to blow or melt snow and ice from aircraft surfaces. 
- Infrared heating de-icing systems consist of an open hangar-type structure with infrared generators suspended from the ceiling. The infrared wavelengths are targeted to heat ice and snow, and minimize heating of aircraft components.

- Aircraft may also be stored in a hangar to prevent snow or ice from accumulating if a storm event is expected.

\section{Chemical Method}

All chemical de-icers share a common working mechanism: they chemically prevent water molecules from binding above a certain temperature that depends on the concentration. This temperature is below $0^{\circ} \mathrm{C}$, the freezing point of pure water. Sometimes, there is an exothermic dissolution reaction that allows for an even stronger melting power. The following list contains the most-commonly used de-icing chemicals and their typical chemical formula:

Inorganic salts, like:

- Sodium chloride, $\mathrm{NaCl}$, (commonly known as table salt)

- Magnesium chloride, $\mathrm{MgCl}_{2}$, reduces working temperature of salt

- Calcium chloride, $\mathrm{CaCl}_{2}$, reduces working temperature of salt

- Potassium chloride, KC

Organic compounds, such as:

- Calcium magnesium acetate, $\mathrm{CaMg}_{2}\left(\mathrm{CH}_{3} \mathrm{COO}\right)_{6}$

- Potassium acetate, $\mathrm{CH}_{3} \mathrm{COOK}$

- Potassium formate, $\mathrm{CHO}_{2} \mathrm{~K}$

- Sodium formate HCOONa

- Calcium formate, $\mathrm{Ca}(\mathrm{HCOO})_{2}$

- Urea, $\mathrm{CO}\left(\mathrm{NH}_{2}\right)_{2}$, a common fertilizer

- Agricultural by-products (generally used as additives to sodium chloride)

Alcohols, diols and polyols (these are antifreeze agents and scarcely used on roads):

- Methanol, $\mathrm{CH}_{4} \mathrm{O}$

- Ethylene glycol, $\mathrm{C}_{2} \mathrm{H}_{6} \mathrm{O}_{2}$

- Propylene glycol, $\mathrm{C}_{3} \mathrm{H}_{8} \mathrm{O}_{2}$

- Glycerol, $\mathrm{C}_{3} \mathrm{H}_{8} \mathrm{O}_{3}$

\section{TYPES OF DE-ICING FLUIDS}

The Society of Automotive Engineers publishes standards for four different types of aviation deicing fluids [01]:

1. Type I fluids have a low viscosity, and are considered "unthickened". They provide only short term protection because they quickly flow off surfaces after use. They are typically sprayed on hot $\left(55-80^{\circ} \mathrm{C}\right)$ at high pressure to remove snow, ice, and frost. Usually they are dyed orange to aid in identification and application.

2. Type II fluids are pseudoplastic, which means they contain a polymeric thickening agent to prevent their immediate flow off aircraft surfaces. Typically the fluid film will remain in place until the aircraft attains almost $200 \mathrm{~km} / \mathrm{h}$, at which point the viscosity breaks down due to shear stress. The high speeds required for viscosity breakdown means that this type of fluid is useful only for larger aircraft. These fluids are generally light yellow in color.

3. Type III fluids can be thought of as a compromise between type I and type II fluids. They are intended for use on slower aircraft, with a rotation speed of less than 100 knots. They are generally light yellow in color.

4. Type IV fluids meet the same AMS standards as type II fluids, but they provide a longer holdover time. They are typically dyed green to aid in the application of a consistent layer of fluid.

Deicing fluids containing thickeners (types II, III, and IV) are also known as anti-icing fluids, because they are used primarily to prevent icing from re-occurring after an initial de-icing with a type I fluid. [02]

\section{DE-ICING USAGE STATISTICS}

The amount of fluid necessary to de-ice an aircraft depends on a wide variety of factors. Deicing a large commercial aircraft typically consumes between 2000 and 4000 litres of diluted fluid. The total annual usage of deicing fluids in the U.S. is estimated to be approximately 25 million litres. According to [10], $77.1 \%$ is Type I (Propylene Glycol), 11.4\% Type IV Propylene Glycol, 10.3\% Type I Ethylene Glycol and 1.2\% Type IV Ethylene Glycol. 
The cost of fluid varies widely due to market conditions. The amount deicing service companies charge end users is generally in the range of US $\$ 8$ to US\$12 per diluted gallon which works out as US $\$ 2,1$ to US $\$ 3,2$ per litre, FY 2012 [12].

\section{MEASUREMENT OF PERFORMANCE OF DE-ICING FLUIDS}

De-icing fluid performance is measured by holdover time, HOT, which is the length of time an aircraft can wait after being treated prior to takeoff. Holdover time is influenced by the ambient temperature, wind, precipitation, humidity, aircraft skin temperature, and other factors. For Type I fluids, the holdover time is only about five to 15 minutes, so the aircraft must take off immediately or else wait to be deiced again. Type IV fluids generally provide a holdover time between 30 and 80 minutes.

Deicing fluids work best when they are diluted with water. For example, undiluted deicing fluid (type I ethylene glycol), has a freezing point of $-28{ }^{\circ} \mathrm{C}$. Water, of course, freezes at $0{ }^{\circ} \mathrm{C}$. However, a mixture of $70 \%$ deicing fluid and $30 \%$ water freezes below $-55{ }^{\circ} \mathrm{C}$. This phenomenon is known as the eutectic concentration, and it is related to the freezing point of the mixture, which is at the lower point than either of the component substances.

Depending on the manufacturer, deicing fluids may be sold in concentrated or pre-diluted formulations. Dilution, where necessary, must be done according to ambient weather condition and the manufacturer's instructions in order to minimize costs while maintaining safety.

The dilution of a particular sample of fluid, and hence its freezing point, can be easily confirmed by measuring its refractive index with a refractometer, and looking up the result in the de-icing fluid manufacturer's tables.

\section{ENVIRONMENTAL IMPACT OF DE-ICING MATERIALS}

De-icing salts such as sodium chloride or calcium chloride leach into the soils, where the ions, especially the cations, may accumulate and eventually become toxic to the organisms and plants growing in these soils. The chemicals could also reach water bodies in concentrations that are toxic to the ecosystems. Organic compounds are biodegraded and may cause oxygen-depletion issues. Small creeks and ponds with long turnover time are especially vulnerable.

Propylene glycol used to de-ice aircraft can contaminate drinking water supplies and harm aquatic life. Some airports are now capturing and treating de-icing runoff before allowing it to enter waterways.

\section{INFRARED HEATING DE-ICING METHOD}

Infrared heating is the transmission of energy by means of electromagnetic waves. Infrared energy is invisible and travels at the speed of light in straight lines from the heat source to all surfaces and objects without significantly heating the space through which it passes. This heating process is much faster than conventional heating mechanisms used by conventional de-icing methods, convection or conduction, where the de-icing fluid spray is cooled by ambient air.

Infrared-based aircraft de-icing systems offer two advantages over traditional glycol-based de-icing methods. From an environmental standpoint, they can greatly reduce the amount of glycolbased fluids used for aircraft de-icing, while from an operational standpoint, they are relatively inexpensive to operate, as they use natural gas or propane as fuel. [13]

Infrared de-icing systems are currently used at John F. Kennedy, Newark Liberty and Rhinelander-Oneida County (Wisconsin) airports, where they have been demonstrated to be very effective.

It is necessary to stress that any infrared de-icing facility must take into account the physical characteristics of all aircraft that will be used for. It refers to the maximum tail height, the shape of tails, maximum wingspans, and differences in the length and width of the fuselage. The site selected for an infrared de-icing system must comply with the same FAA regulations that apply to glycol-based aircraft de-icing facilities, including aircraft separation rules, air traffic control tower line-of-sight criteria, and requirements to not interfere with radar signals, navigational aides, and airport lighting. FAA issued a new Advisory Circular in 2005 specifically for infrared de-icing facilities. As with traditional aircraft de-icing facilities, an infrared de-icing facility must provide taxiways that allow aircraft to bypass the de-icing facility.

According to documents provided by Radiant using data from the JFK facility for the 2010-2011 winter season, average snow/ice removal time 
for a Boeing 737-size aircraft was approximately 17 minutes from the time the aircraft rolls into the hangar until it exits. Boeing 747-300-size aircraft averaged 19 minutes. This means that three to four 737s or two 747s can be de-iced per hour, versus approximately 45 to 90 minutes per aircraft with conventional glycol de-icing. [14]

\section{CONCLUSION}

The main objective of this paper was to address the ice formation of aircraft surfaces and its removal through de-icing process as a mechanism of the motion in Mirce Mechanics. Ice-building on aircraft can take place in two ways: in flight or on the ground. This paper focuses on the formation of ice on the ground, resulting from the falling precipitations that freeze on the upper surfaces of the wings and tail in certain environmental conditions. The operators manage this process by de-icing the plane with a fluid, typically propylene glycol, at the airport, imminently to the take off.

Consequently, this paper addressed the de-icing, methods, fluids, procedures, statistics and associated environmental impacts with objectives to understand them in order to manage them, starting from the design processes of the aircraft itself, through the design of de-icing facilities with detail analysis of the chemical composition of the de-icing fluid and their usage.

Aircraft de-icing process is on vital important for the safe and reliable operation of thousands of daily flights that affected by this natural phenomena which comes with seasonal periodicity and as such has monetary impact of doing it and possible catastrophic consequences of not doing it.

It is believed that this paper will make a positive contribution to the further understandings of this natural phenomenon on one hand, and effective management of its impacts on aircrafts despatch reliability and resources invested to achieve it, on the other.[10]

\section{REFERENCES}

1) Airport Cooperative Research Program. De-icing Planning Guidelines and Practices for Stormwater Management Systems. Report 14.

2) Environmental Protection Agency, Environmental Impact and Benefit Assessment for Proposed Effluent Limitation Guidelines and Standards for the Airport De-icing Category. July 2009.
3) Federal Aviation Administration, Ground Deicing and Anti-icing Program, Circular No. 120-60B.

4) Federal Aviation Administration, Ground Deicing and Anti-lcing Training and Checking, Circular No. 135-16.

5) Federal Aviation Administration, Pilot Guide Large Aircraft Ground De-icing, Circular No. 120-58.

6) Federal Aviation Administration. Ground Deicing Using Infrared Energy. Circular No. 120-89.

7) Hessing, H., Knoesel, E., \& Sharkey, I. Infrared Aircraft De-icing Facility at John F. Kennedy International Airport. Retrieved from http://www.mmtmagazine.org/spring_06_ jfk_de-icing.html

8) http://www.ainonline.com/aviation-news/aviation-international-news/2013-10-02/infrared-de-icing-speeds-process-and-reducescost

9) http://www.ntsb.gov/safety/safety-alerts/ Documents/SA_006.pdf

10)h t t p : / / s p u t n i knew s. com / rus sia/20130716/182264029.htm|\#ixzz3bXHP6haC

11) http://www.mak.ru/russian/investigations/2012/ report_vp-byz.pdf

12) Knezevic, J., Atoms and Molecules in Mirce Mechanics Approach to Reliability, SRESA Journal of Life Cycle Reliability, pp. 15-25, Vol 1, Issue No. 1, January-March 2012,

13) Todorović, J., Upravljanje održavanjem na bazi rizika, Journal of Applied Engineering Science, no. 1, pp. 23-33, Beograd, Srbija, 2009.

14) Zaczyk, I., Impact of Cosmic Radiation on Aviation Reliability and Safety, Journal of Applied Engineering Science, pp 217-223, No. 4, Year 2013, Vol 11, Belgrade, Serbia.

Paper sent to revision: 01.08.2015.

Paper ready for publication: 15.09.2015. 